\title{
IN-PLANT TESTING OF HIGH-EFFICIENCY HYDRAULIC SEPARATORS
}

\author{
Report Type \\ Annual Technical Progress Report (Phase II) \\ Reporting Period Start Date: \\ July 21, 2004 \\ Reporting Period End Date: \\ July 20, 2005 \\ Principal Authors \\ G. H. Luttrell, R.Q. Honaker, R.C. Bratton, \\ T.C. Westerfield and J. N. Kohmuench
}

Report Submission Date

May 22, 2006

DOE Award Number

DE-FC26-03NT41789

Prime Contractor

Virginia Polytechnic Institute \& State University (Virginia Tech)

Office of Sponsored Programs

Collegiate Square, 460 Turner Street, Suite 306 (0170)

Blacksburg, VA 24060

\section{$\underline{\text { Team Members/Subcontractors }}$}

Virginia Tech

Blacksburg, VA 24060

Eriez Manufacturing, Inc.

Erie, PA

KenAmerican Resources

Central City, KY
University of Kentucky

Lexington, $\mathrm{KY}$

The Mosaic Company

Mulberry, FL

TECO Coal Corporation Feds Creek, KY 


\section{DISCLAIMER}

This report was prepared as an account of work sponsored by an agency of the United States Government. Neither the United States Government nor any agency thereof, nor any of their employees, makes any warranty, express or implied, or assumes any legal liability or responsibility for the accuracy, completeness, or usefulness of any information, apparatus, product, or process disclosed, or represents that its use would not infringe privately owned rights. Reference herein to any specific commercial product, process, or service by trade name, trademark, manufacturer, or otherwise does not necessarily constitute or imply its endorsement, recommendation, or favoring by the United States Government or any agency thereof. The views and opinions of authors expressed herein do not necessarily state or reflect those of the United States Government or any agency thereof. 


\begin{abstract}
Hydraulic separators are commonly used for particle size classification and gravity concentration of minerals and coal. Unfortunately, the efficiency of these processes can be quite low due to poor equipment design and variations in feed consistency. To help alleviate these problems, an industry-driven $R \& D$ program has been undertaken to develop a new generation of hydraulic separators that are more efficient and less costly to operate and maintain. These units, which are commercially called the CrossFlow separator and HydroFloat separator, have the potential to improve performance (separation efficiency and throughput) and reduce operating costs (power consumption, water and reagent usage). In Phase I of this project, laboratory and pilot-scale test units were evaluated at various industrial sites in both the coal and mineral industries. Based on promising results obtained from Phase I, full-scale prototypes were purchased and installed by a major U.S. phosphate producer and a large eastern U.S. coal company. The test data obtained from these sites demonstrate that significant performance improvements can be realized through the application of these high-efficiency separators.
\end{abstract}




\section{TABLE OF CONTENTS}

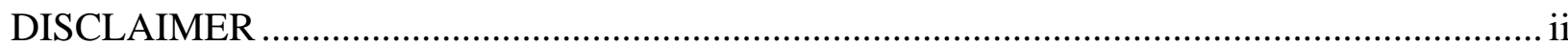

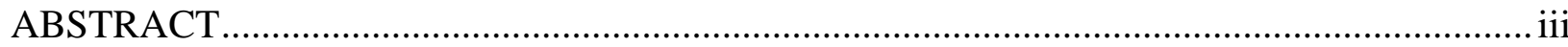

TABLE OF CONTENTS................................................................................................... iv

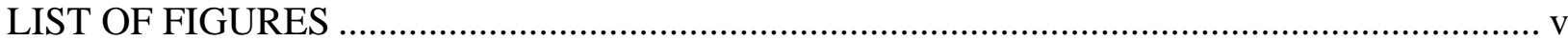

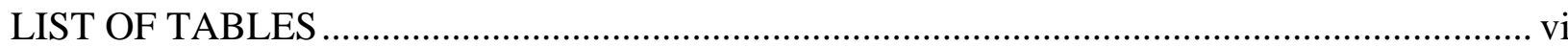

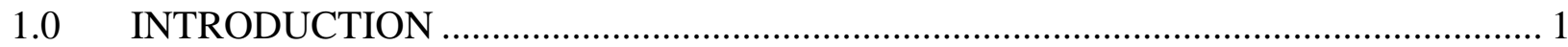

$1.1 \quad$ Hydraulic Classification..................................................................................... 1

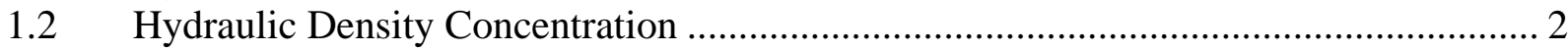

1.3 High-Efficiency Hydraulic Separators........................................................................ 4

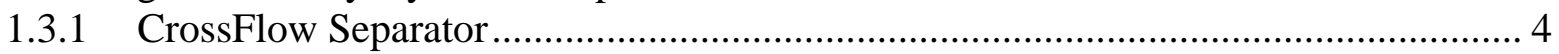

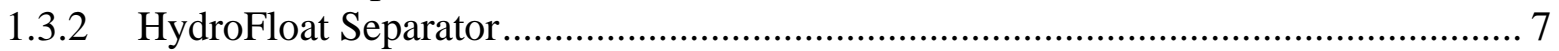

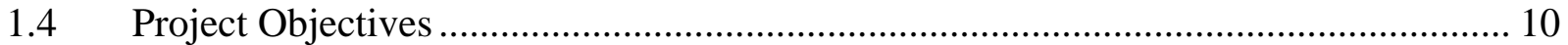

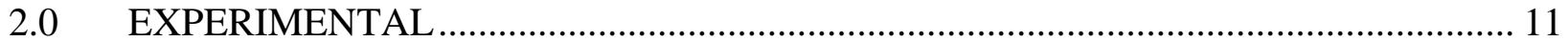

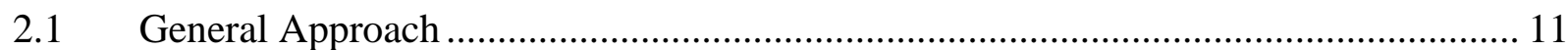

2.2 Project Tasks for Phase I - Pilot-Scale Testing .................................................... 12

Task 1 - Phase I Project Planning .................................................................................. 12

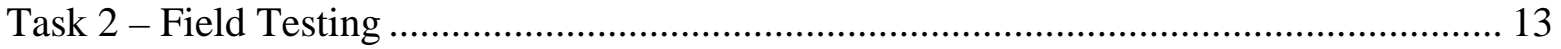

Task 3 - Process Evaluation......................................................................................... 14

Task 4 - Phase I Sample Analysis............................................................................ 14

Task 5 - Phase I Project Report.......................................................................................... 15

2.2 Project Tasks for Phase II - Prototype Testing............................................................. 15

Task 6 - Phase II Project Planning .............................................................................. 15

Task 7 - Scale-up Design and Engineering ................................................................... 15

Task 8 - Fabrication, Installation, Commissioning .............................................................. 16

Task 9 - Performance Testing .......................................................................................... 16

Task 10 - Phase II Sample Analysis ................................................................................. 17

Task 11 - Technical Evaluation ....................................................................................... 17

Task 12 - Final Project Report ............................................................................. 17

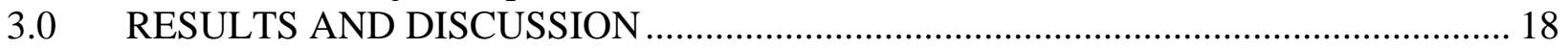

3.1 Phosphate Size Classification Using the CrossFlow Classifier ..................................... 18

3.1.1 Pilot-Scale Test Results ............................................................................. 18

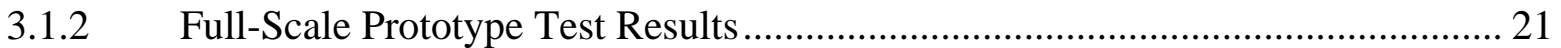

3.2 Phosphate Upgrading Using the HydroFloat Concentrator ........................................... 23

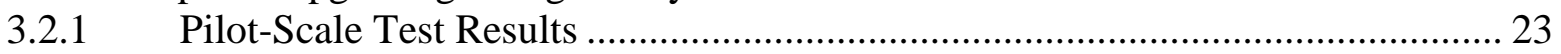

3.2.2 Full-Scale Prototype Test Results .......................................................................... 25

3.3 Fine Coal Cleaning Using the CrossFlow Concentrator............................................... 28

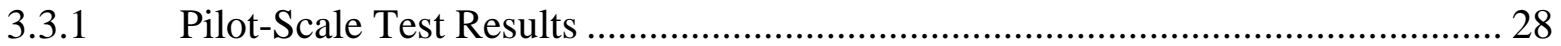

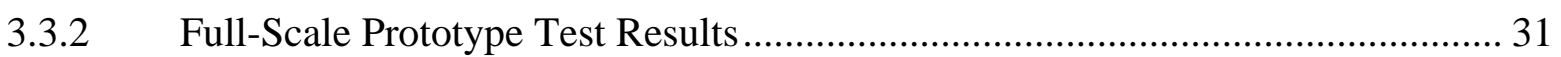

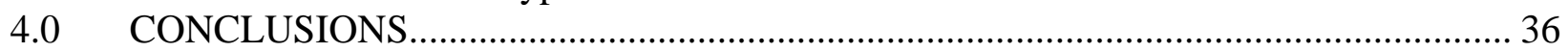

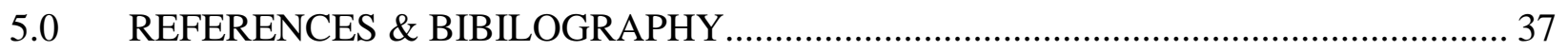




\section{LIST OF FIGURES}

Figure 1.1. Schematic drawings comparing a traditional teeter-bed separator (left) with the advanced CrossFlow classifier (right).

Figure 1.2. Comparison of water flow velocities in different classifiers ............................... 6

Figure 1.3. Schematic drawing of the HydroFloat separator. ................................................ 8

Figure 3.1. Example of a CrossFlow partition curve ....................................................... 19

Figure 3.2. Imperfection versus superficial solids feed rate.............................................. 20

Figure 3.3. Particle cut size versus fluidization water rate............................................... 21

Figure 3.4. Recovery versus insol content for different test runs....................................... 26

Figure 3.5. Recovery versus BPL content for different test runs ....................................... 26

Figure 3.6. Recovery versus product ash for the plus 100 mesh coal ................................... 30

Figure 3.7. Mass yield versus product sulfur for the plus 100 mesh coal .............................. 30

Figure 3.8. Mass balance sheet for the full-scale prototype CrossFlow................................. 32

Figure 3.9. Photograph of the installed full-scale CrossFlow separator ................................. 32

Figure 3.10. Experimental results from three series of full-scale CrossFlow tests .................... 34 


\section{LIST OF TABLES}

Table 2.1. Listing of project tasks conducted in Phase I and II ......................................... 12

Table 3.1. Conditions used for the CrossFlow pilot-scale tests .......................................... 18

Table 3.2. Comparison of full-scale conventional and CrossFlow classifiers ........................ 18

Table 3.3. Test conditions for the pilot-scale HydroFloat concentrator ............................... 24

Table 3.4. Test results for the pilot-scale HydroFloat concentrator.................................... 24

Table 3.5. Comparison of power and reagent demand ................................................ 27

Table 3.6. Test conditions used for the on-site pilot-scale testing of the CrossFlow unit ........ 29

Table 3.7. Results of a long duration (8 hr) CrossFlow test under optimum conditions .......... 35 


\subsection{INTRODUCTION}

\subsection{Hydraulic Classification}

Hydraulic separators are frequently used in the minerals processing industry to classify fine particle according to size and/or density. Although many devices have been developed over the years, a technique that has been gaining popularity in recent years is the teeter-bed separators. These devices, which are also commonly called hindered-bed or fluidized-bed separators, make use of differential particle settling rates to segregate particles according to size, shape, and/or density. The tradition design consists of an open top vessel into which elutriation water is introduced through a series of distribution pipes evenly spaced across the base of the device. During operation, feed solids are injected into the upper section of the separator and are permitted to settle. The upward flow of elutriation water creates a fluidized bed of suspended particles within the separator. The small interstices within the bed create high interstitial liquid velocities that resist the penetration of the slow settling particles. As a result, small particles accumulate in the upper section of the separator and are eventually carried over the top of the device into a collection launder. Large particles, which settle at a rate faster than the upward current of rising water, eventually pass through the fluidized bed and are discharged out one or more restricted ports through the bottom of the separator.

It is obvious from the above description that quiescent flow conditions must exist within the separator to maintain a high efficiency. Excessive turbulence or changes in flow conditions can result in the unwanted misplacement of particles. Unfortunately, current hydraulic separators utilize a feed injection system that discharges directly into the main separation chamber. These simplistic feed systems typically consist of a vertical pipe that terminates approximately onethird of the way into the main separator body. The pipe discharge is usually equipped with a 
dispersion plate to laterally deflect the feed slurry, but this approach creates turbulence within the separator that is detrimental to an efficient separation. In addition, the water that is injected with the feed solids must also report to the overflow launder. As a result, the rise velocity of the water is substantially increased at the feed injection point. Above the feed point, the liquid rise velocity is the sum of the elutriation water and the feed water flow rates. This discontinuity often results in a secondary interface of fluidized solids within the separator. In fact, at higher feed rates, the volume of water associated with the feed slurry is often greater than the volume of elutriation water; thus severely affecting the separation performance. Throughput capacities are also limited in conventional hydraulic separators due to the detrimental impact of feed water on unit performance.

Equipment maintenance is also important issue in the design of a hydraulic separator. Conventional teeter-bed designs use a series of lateral pipes located in the base of the separation zone. These pipes are perforated at regular intervals with large numbers of small diameter holes. Elutriation water is injected through these holes over the entire cross-section of the separator. The large water flow rates combined with the small injection hole diameters leave the device susceptible to frequent blockage/plugging due to contaminants in the process water. When several orifices become blocked, a dead zone occurs in the fluidization chamber resulting in a loss of performance in this area. As a result, conventional teeter-bed separators have an inherent design flaw that limits both the capacity and efficiency of the separator.

\subsection{Hydraulic Density Concentration}

In addition to particle sizing applications, teeter-bed separators are also frequently used to separate various minerals based on differences in particle density. In this case, the coarse highdensity particles settle against the rising flow of water and build a bed of teetering solids. This 
bed of high-density solids has an apparent density much higher than the elutriation water. Since particle settling velocity is driven by the density difference between the solid and liquid phase, the settling velocity of the particles is reduced by the increase in apparent density of the teetering bed. This artificial density forces low-density particles to report to the overflow of the separator and high-density particles to report to the underflow.

Some common examples of density-based teeter-bed applications include the separation of coal from rock, silica from iron ore, and silica from various heavy minerals (zircon and ilmenite). Unfortunately, the plant data indicate that efficient concentration can only be achieved if the particles are in the size range of 200 mesh to several millimeters and if the particle size ratio (top size to bottom size) is less than about four-to-one. In practice, coarse low-density particles will tend to gather at the surface of the teeter-bed interface because the elutriation water velocity is not sufficient to transport these large particles into the overflow launder. The large particles continue to gather at the bed interface until mass action forces them into the teeter bed, where they eventually misplaced into the high-density product. This inherent inefficiency can be partially corrected by increasing the elutriation water velocity to convey the coarser low-density solids into the overflow. Unfortunately, this approach is harmful to the concentrate grade since it also causes the finer high-density solids to be misplaced into the overflow launder. Because of theses shortcomings, the separation efficiency obtained using teeter-bed separators is often poor in industrial operations. In most cases, the valuable component (i.e., coal, iron ore, ilmenite and zircon) frequently must be reprocessed in "polishing" circuits to achieve the desired product quality. The problem is that conventional teeter-bed separators are inherently inefficient when used to treat mineral assemblages that have either a wide particle size distribution or a narrow density distribution. 


\subsection{High-Efficiency Hydraulic Separators}

From the discussion presented above, it is apparent that design improvements are needed to correct inefficiencies associated with conventional hydraulic separators. In response to this need, a new generation of teeter-bed separators known as the "CrossFlow Separator" and “HydroFloat Separator” is under development by Eriez Manufacturing in conjunction various research universities and mineral producers. These new high-efficiency separators incorporate novel design features to improve performance (separation efficiency and throughput) and reduce operating costs (power consumption, water usage and reagent dosage). Both of these innovative technologies are high-tech variations of the conventional teeter bed separator concept. As such, these high-efficiency units can be readily adopted by industry once the operational knowledge base has been fully developed and the merits have been demonstrated in an industrial environment.

\subsubsection{CrossFlow Separator}

Figure 1.1 shows schematic of the CrossFlow Separator. Compared to a conventional hydraulic classifier, the CrossFlow design uses an improved feed delivery system that gently introduces the feed slurry across the top of the separator as opposed to injecting the slurry at a high velocity directly into the teeter-bed. As previously stated, high slurry feed volumes create turbulent mixing that has a detrimental impact on separator performance. In the new feed delivery system, the feed velocity is reduced using a transition box. The purpose of this box is two-fold. First, the feed transition box increases the flow area to the full width of the separator so that the slurry velocity, and any associated turbulence, is minimized. The second unique feature is its ability to tangentially feed the separator. This stilling-well, which is located at the top of the 

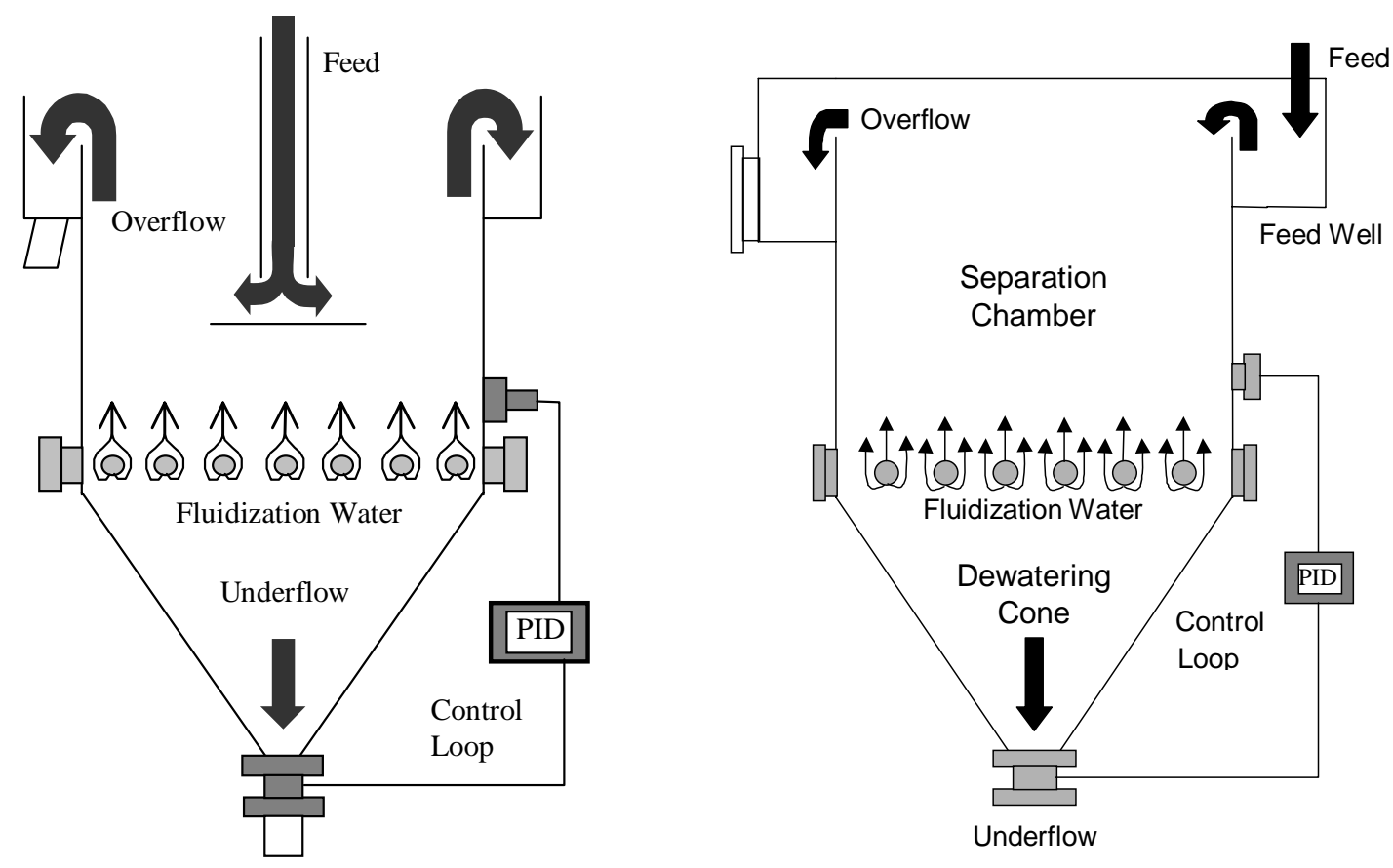

Figure 1.1. Schematic drawings comparing a traditional teeter-bed separator (left) with the advanced CrossFlow classifier (right).

separator, smoothly passes the feed slurry horizontally across the top of the cell and into the overflow launder. Compared to conventional systems, the feed introduction system ensures that variations in feed slurry characteristics (e.g., solids content) do not impact separator performance. In the CrossFlow, the teeter-water velocity remains constant throughout the separation chamber at all times, while the velocity in a conventional classifier generally increases above the feed addition point (Figure 1.2). A duck plate is also located at the discharge end of the feed introducer to prevent short-circuiting of solids directly to the overflow launder.

Another design feature incorporated into CrossFlow classifier is the improved water distribution system. A novel approach has been developed that incorporates a baffle plate to disperse the elutriation water across the base of the separator. In this design, a horizontal slotted plate is located at the base of the separation chamber. Water is introduced beneath the plate through a series of large diameter holes $(>1.25 \mathrm{~cm})$. However, unlike existing separators, these 

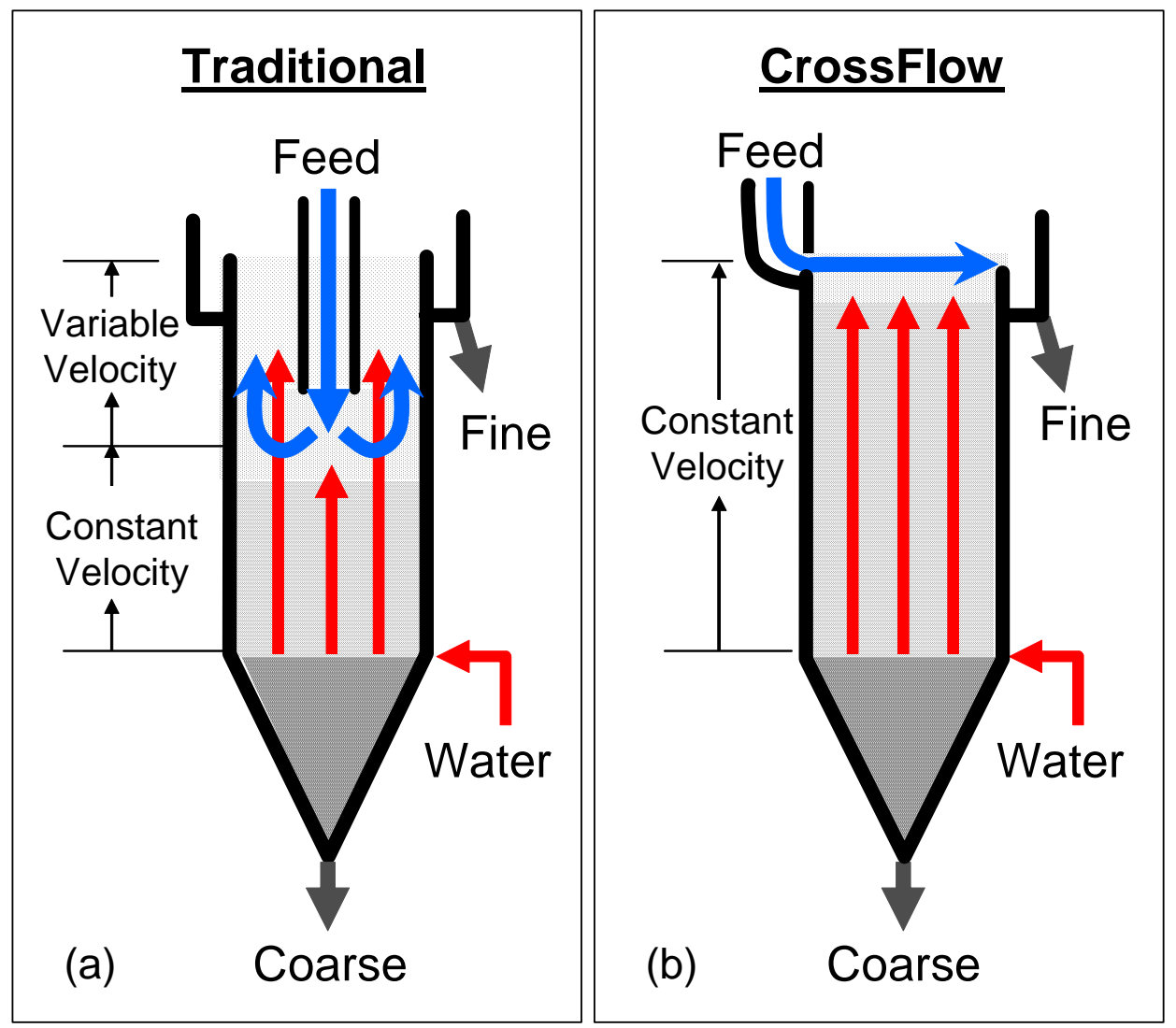

Figure 1.2. Comparison of water flow velocities in different classifiers.

orifices are located at distant intervals (typically $>15 \mathrm{~cm}$ ) and serve simply to introduce the water, while water dispersion is achieved by the baffle plate. This modification essentially eliminates problems associated with distributor pipe plugging. The combined use of the improved feed injection system and simplified water distribution system makes it possible to increase both the separation efficiency and throughput capacity while eliminating mechanical problems associated with traditional designs. Because of the higher throughput capacity, the operating demands in terms of power, water consumption and maintenance are lower for the CrossFlow when reported on a per ton of concentrate basis. 


\subsubsection{HydroFloat Separator}

It is generally accepted that teeter bed technologies, such as the CrossFlow design, can only be applied to mineral systems that have (i) a relatively narrow particle size distribution and (ii) a moderately large difference in particle densities. To overcome these limitations, technical personnel at Eriez Manufacturing have been working with industry to develop a novel air assisted hydraulic concentrator called the HydroFloat separator. This innovative process, which is shown in Figure 1.3, combines the flexibility of a flotation process with the high capacity of a density separator.

During operation, particles in the feed stream are treated with a reagent (called a collector) so that the surface of one or more of the mineral particles is made hydrophobic. The reagentized feed slurry is then introduced into the top of the separator where the feed particles are allowed to settle into the teeter bed at a rate dictated by their size and density. The teeter bed is continuously aerated by injecting compressed gas and a small amount of frothing agent into the fluidization water. The gas is dispersed into small air bubbles by circulating the water through a high-shear mixer in closed-loop with a centrifugal pump. Because of differences in wettability, the air bubbles in the fluidization water become selectively attached to hydrophobic particles within the teeter bed, thereby reducing their effective density. The lighter bubbleparticle aggregates rise to the top of the denser teeter bed and are collected as overflow from the top of the separation chamber. In contrast, air bubbles do not become attached to hydrophilic particles. These particles continue to move down through the teeter bed and are eventually discharged as a high solids stream (e.g., 75\% solids) through a control valve at the bottom of the separator. 


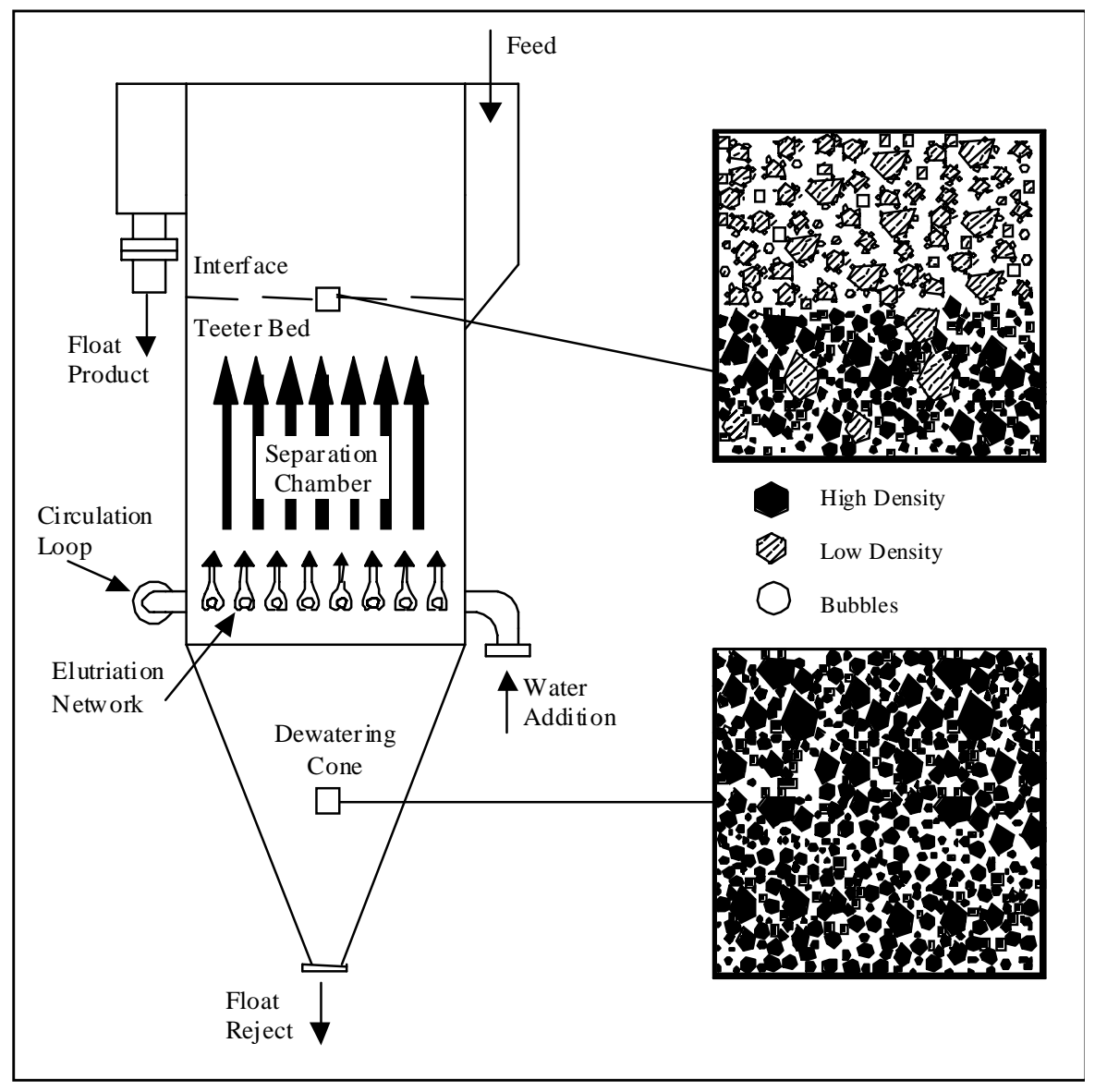

Figure 1.3. Schematic drawing of the HydroFloat separator.

The HydroFloat separator makes it possible to apply density separation technology to nearly any mineral system, even if the natural densities of the valuable component and gangue are the same. In this case, the surface wettability of different particle species can selectively modified to create lighter bubble-particle aggregates that can be separated from unwanted gangue particles. For some systems, such as coal, the valuable particles are naturally hydrophobic and will spontaneously attach to air bubbles, while associated mineral contaminants are hydrophilic and will not attach. Other systems, such as iron ore with a silica contaminant, require chemical activation of the silica to promote bubble-particle attachment. The method for 
chemical activation using reagents known as collectors is well known and is routinely used for the selective recovery of fine particles (less than $0.2-0.3 \mathrm{~mm}$ ) using froth flotation processes.

The HydroFloat separator has several potential advantages compared to conventional froth flotation cells. The use of a fluidized bed significantly improves the recovery of coarse particles by reducing turbulence, enhancing buoyancy, increasing particle retention time, and improving bubble-particle contacting. In addition, the new technology significantly reduces energy consumption since no mechanical agitator is required. The system is also capable of lowering capital and installation costs since less total cell volume is required per unit of throughput capacity due to the high solids content within the teeter bed.

The unique design features of the HydroFloat separator make it ideally suited for recovering very coarse particles that are too large to be upgraded by existing froth flotation processes. This capability is very important to several industries (potash, phosphate, coal, etc.) that commonly have difficulties in recovering the coarser particles in the feeds to the plant flotation circuits. One reason for the improved recovery of coarse particles is the upward flow of elutriation water that helps to lift the larger particles into the product launder. The high content of solids and quiescent flow conditions within the teeter bed separator also serve as an ideal environment for collision and adhesion of air bubbles and particles. In addition, the high solids content within the teeter bed separator makes it possible to treat large tonnages in a very compact volume as compared to conventional flotation separations which are conducted at very low solids contents using large volume cells. Also, substantial energy savings are possible since the countercurrent flow of feed particles and elutriation water eliminates the need for intense agitation normally required in conventional flotation machines. 


\subsection{Project Objectives}

The primary objective of this project is to demonstrate the enhanced capabilities of novel high-efficiency hydraulic separators for particle classification and concentration in the mineral and coal industries. Preliminary studies suggest that these technologies offer better separation efficiency (e.g., higher recovery, improved grade, and increased capacity) and lower operating cost (e.g., lower consumption of electrical power, process water, and chemical reagents) than conventional processes that are currently used for mineral and coal beneficiation. To meet this objective, a two-phase test program was conducted at several industrial plant sites.

The objective of the Phase I effort was to systematically establish the effects of key design and operating variables on the performance capabilities of these high-efficiency separators. This effort involved extensive field tests conducted using small pilot-scale units at several different mineral processing and coal preparation plants. The pilot-scale tests were necessary to collect data that would be impractical or cost prohibitive to gather in full-scale tests for single industrial sites.

The objective of the Phase II effort was to further refine and demonstrate the effectiveness of the novel separation technologies by designing, installing and evaluating prototype proof-of-concept (POC) separators at commercial sites. This work was required (i) to accurately define the performance capabilities of these high-efficiency processes in an industrial environment, (ii) to provide critical scale-up criteria for the design of larger production units, and (iii) to fully demonstrate the potential economic benefits realized via the implementation of these innovative technologies. 


\subsection{EXPERIMENTAL}

\subsection{General Approach}

To achieve the stated project objectives, a cooperative $R \& D$ program was conducted that involved two major research universities (Virginia Tech and University of Kentucky), a leading manufacturer of process equipment (Eriez Manufacturing, Inc.), and several mineral processing and coal preparation operations (Mosaic Company, TECO Mining and KenAmerica Coal). Virginia Tech, which served as the prime contractor for the effort, provided day-to-day coordination of project activities and was responsible for the set-up, operation, sampling, and evaluation of the proposed test circuits. Personnel from Eriez and the University of Kentucky assisted Virginia Tech in this effort by providing on-site personnel during the field installation and testing programs. These organizations were assisted by personnel from the participating industrial companies who provided critically needed expertise related to the operation of their plants. Engineering personnel from these companies also played an active role in the on-site coordination of the fieldwork, assisted in the analysis, review, and interpretation of the test data, and provided a variety of on-site services such as mechanical/electrical services, sample preparation, and sample analysis.

For management reasons, the project work was performed in two distinct phases encompassing twelve individual tasks (see Table 2.1). In Phase I, continuous pilot-scale test circuits were set up and tested at several industrial sites. For phosphate operations, the pilot-scale tests focused primarily on improving the performance of mineral flotation circuits using the HydroFloat separator. Experimental studies were, however, also conducted at this site to evaluate the ability of the CrossFlow classifier to simplify plant circuitry and reduce operating costs (i.e., power, water and reagent costs). For the coal operations, the pilot-scale test work was conducted 
Table 2.1. Listing of project tasks conducted in Phase I and II.

\begin{tabular}{cc}
\hline Phase I - Pilot-Scale Testing & Phase II - Prototype Testing \\
\hline Task 1 - Phase I Project Planning & Task 6 - Phase II Project Planning \\
Task 2 - Field Testing & Task 7 - Scale-Up Design/Engineering \\
Subtask 2.1 - Equipment Setup & Subtask 7.1 - Flowsheet Design \\
Subtask 2.2 - Shakedown Testing & Subtask 7.2 - Equipment Design \\
Subtask 2.3 - Detailed Testing & Task 8 - Fabrication/Commissioning \\
Task 3 - Process Evaluation & Task 9 - Performance Testing \\
Task 4 - Phase I Sample Analysis & Task 10 - Detailed Evaluation \\
Task 5 - Phase I Project Report & Task 11 - Final Project Report \\
\hline
\end{tabular}

using the high-efficiency CrossFlow unit to improve the recovery and quality of saleable products from their fine coal processing circuits. The Phase I activities required approximately 18 months of work for project planning, field testing, process evaluation, sample analysis and reporting. Research personnel from the participating universities, equipment manufacturer, and mining companies jointly conducted these activities.

After successfully completing Phase I activities, suitable industrial locations were identified for the installation of production-scale prototypes of both the HydroFloat and CrossFlow technologies. Approximately 18 months of additional work was required in Phase II for additional project planning, scale-up design/engineering, fabrication and commissioning, performance testing, detailed evaluation and reporting. The equipment manufacturer and two industrial participants (one mineral and one coal) were largely responsible for the completion of these on-site demonstrations.

\subsection{Project Tasks for Phase I - Pilot-Scale Testing}

Task 1 - Phase I Project Planning

Prior to initiation of experimental work, a Detailed Project Work Plan was prepared and submitted to DOE for approval. The work plan provided a detailed description of the proposed 
test program, experimental procedures, analytical methods, and reporting guidelines for the implementation and completion of the proposed Phase I and Phase II efforts.

\section{Task 2 - Field Testing}

The Phase I field-testing involved (i) equipment setup, (ii) shakedown testing, and (iii) detailed testing of pilot-scale separators. Subtask 2.1 (Equipment Setup) focused on the transportation and installation of pilot-scale test units for each industrial site. For mineral operations, it was also necessary to install conditioning tanks in order to fully evaluate the circuit configurations. In addition, a wide variety of ancillary equipment, such as pumps, sumps, meters, etc., were also installed at each test site. Personnel from Eriez Manufacturing and the participating universities coordinated this effort in conjunction with staff from the participating mining companies. Subtask 2.2 (Shakedown Testing) was then initiated resolve any unexpected operational problems that occurred at each site and to confirm that pumping capacities, pipe sizes, electrical supplies, control systems, etc., are adequate. Personnel from the participating universities and Eriez Manufacturing will be largely responsible for the completion of this subtask. Finally, in Subtask 2.3 (Detailed Testing), several series of detailed tests were conducted using the pilot-scale test units to investigate the effects of the key operating and design parameters on separator performance. Important design parameters included (i) feed injection depth, (ii) distributor design, (iii) and baffle configuration. Key operating variables included (i) fluidization water rate, (ii) solids mass feed rate, (iii) volumetric slurry feed rate, (iv) teeter bed depth, and (v) reagent dosage (when required). When appropriate, sampling campaigns were also be conducted at each of the industrial site to establish the baseline performance of the existing plant equipment so that the data could be fairly compared with that obtained from the high-efficiency hydraulic separators. The responsibility for completing this 
work was jointly shared between the university personnel and technical staff from the mineral and coal producers.

\section{Task 3 - Process Evaluation}

This task involved the compiling and archiving of the raw test data. In most cases, data analysis consisted of evaluating the individual and combined capabilities of the various processing circuits examined at the industrial sites. This subtask ran concurrently with the test work conducted in Task 2 at each of the industrial test sites. Items addressed in the evaluation

included (i) a summary of all the major experimental data, engineering analyses, computations, and test results; (ii) synopsis of the individual and combined capabilities of the various unit operations in terms of separation performance and throughput capacity; (iii) preliminary calculations of mass and liquid flow rates based on data obtained from the pilot-scale test work, and (iv) a complete listing of key operating demands including power consumption, process water usage, and reagent requirements. Criteria used in evaluating process performance included product yield, product recovery, product quality, rejection levels, and separation efficiency. To ensure that the test data are reliable and self-consistent, the experimental data was analyzed and adjusted using a standard mass balance program. Experimental values that were deemed by the mass balance routines to be unreliable were removed from the data set.

\section{Task 4 - Phase I Sample Analysis}

Detailed analyses were conducted on each of the samples collected during the proposed test program. Unless otherwise specified, these analyses were performed in accordance with ASTM procedures and standards. Representative samples were collected around the various pilot-scale unit operations. Mass and liquid flow rates from most streams were directly measured 
using hand samplers or mechanical flow meters. The mass and liquid flow rate of any stream that could not be directly measured was back-calculated from sample assays using the two-product formula.

Task 5 - Phase I Project Report

Technical Progress Reports for Phase I activities were prepared and submitted to DOE on a quarterly basis using a PowerPoint template (provided by DOE). In addition, a written Phase I Topical Report was provided to DOE after the completion of the Phase I activities (Tasks 1-5). The draft report included all major experimental data, engineering analyses, computations, test results, and major findings from the Phase I work.

\section{$2.2 \quad$ Project Tasks for Phase II - Prototype Testing}

\section{Task 6 - Phase II Project Planning}

This task, which was initiated after successfully completing Phase I, involved updating of the Project Work Plan to describe the work activities to be performed under Phase II. The revised plan identified the two test sites (one coal and one phosphate) for the installation of the production-scale prototype. An experimental test plan was also prepared to describe the sampling and analysis required to successfully complete the Phase II work.

\section{Task 7 - Scale-up Design and Engineering}

Subtask 7.1 (Flowsheet Design) involved the development of process flowsheets for the production-scale prototypes. The engineering and design work was completed as a coordinated effort between personnel from Eriez Manufacturing and the participating mining companies. Eriez Manufacturing was solely responsible for completing Subtask 7.2 (Equipment Design), 
which involved the final detailed design and engineering associated with the fabrication and construction of the prototype equipment.

\section{Task 8 - Fabrication, Installation, Commissioning}

This task involved the in-house fabrication of the prototype high-efficiency separators at the Eriez Manufacturing shop facility. Once fabrication was completed, the prototype units were transported to the mine sites and installed by the mining companies. All expenses associated with the purchase and installation of the prototype unit were completely covered by the participating mining companies. All project participants assisted in the final commissioning and shakedown testing of the prototype equipment.

\section{Task 9 - Performance Testing}

After completion of the commissioning work, detailed tests were conducted at each mine site in order to evaluate the capabilities of the prototype equipment. This effort, which included a wide variety of experimental test runs, required approximately three months of dedicated testing at each of the two test sites (one mineral and one coal). In each series of tests, representative samples of the product streams were collected and subjected to the appropriate analytical analysis procedures. When possible, data from existing plant separators were obtained and compared with those obtained using the prototype equipment. Data logs were maintained by plant management to document improvements in separation performance, power consumption, process water usage, and reagent dosage. 
Task 10 - Phase II Sample Analysis

Detailed analyses will be conducted on each of the samples collected during the prototype test program. Unless otherwise specified, these analyses will be performed in accordance with ASTM procedures and standards.

\section{Task 11 - Technical Evaluation}

The raw test data obtained from the testing of the prototype units was compiled and analyzed A preliminary economic evaluation of the prototype installations was also carried out to assess the overall commercialization potential of the proposed high-efficiency hydraulic separators. Items examined in the economic evaluation included (i) total capital costs for the full-scale commercial installation of the proposed circuitry and any required ancillary operations and (ii) expected operation and maintenance costs including electrical power, reagents, and other consumables.

\section{Task 12 - Final Project Report}

Technical Progress Reports were prepared and submitted to DOE on a quarterly basis as PowerPoint files. In addition, a Phase I Technical Progress Report was submitted after completing Phase I (Pilot-Scale Testing) activities as outlined in Tasks 1-5. A Final Project Report is currently being prepared for submission to and review by DOE. 


\subsection{RESULTS AND DISCUSSION}

\subsection{Phosphate Size Classification Using the CrossFlow Classifier}

\subsubsection{Pilot-Scale Test Results}

An on-site test program was conducted at an industrial phosphate plant to evaluate the potential benefits of the CrossFlow separator for particle classification. The 2 x $2 \mathrm{ft}$ pilot-scale unit was installed to partition the $16 \times 150$ mesh plant feed for the existing flotation circuits into narrowly-sized fractions. Comparison tests were also performed using a pilot-scale conventional classifier so that any improvements in sizing performance could be accurately quantified. Table 3.1 provides a summary of the operating conditions examined for each classifier. For each test, representative samples were collected from the feed, overflow, and underflow. The samples were subjected to sieve analysis and the results were mass balanced using a sum-of-least-squares method to assess the reliability of the experimental data. Data that mass balanced poorly were deemed unreliable and eliminated from the analysis.

The mass balanced data were used to construct partition curves for each test run performed for the two classifiers. Figure 3.1 shows an example of a partition curve obtained using the CrossFlow separator. The partition number represents the recovery of dry solids from the feed to the underflow (oversize) product for each size class. The partition curves were used to determine the imperfection (I) for each test. The imperfection is a dimensionless number

Table 3.1. Conditions used for the CrossFlow pilot-scale tests.

\begin{tabular}{ccc}
\hline Test Variable & Conventional & CrossFlow \\
\hline Feed Rate $\left(\mathrm{tph} / \mathrm{ft}^{2}\right)$ & $2-9$ & $1-7$ \\
Feed Solids $(\%)$ & $15-40$ & $15-50$ \\
Water Rate $(\mathrm{gpm})$ & 190 & $40-90$ \\
\hline
\end{tabular}




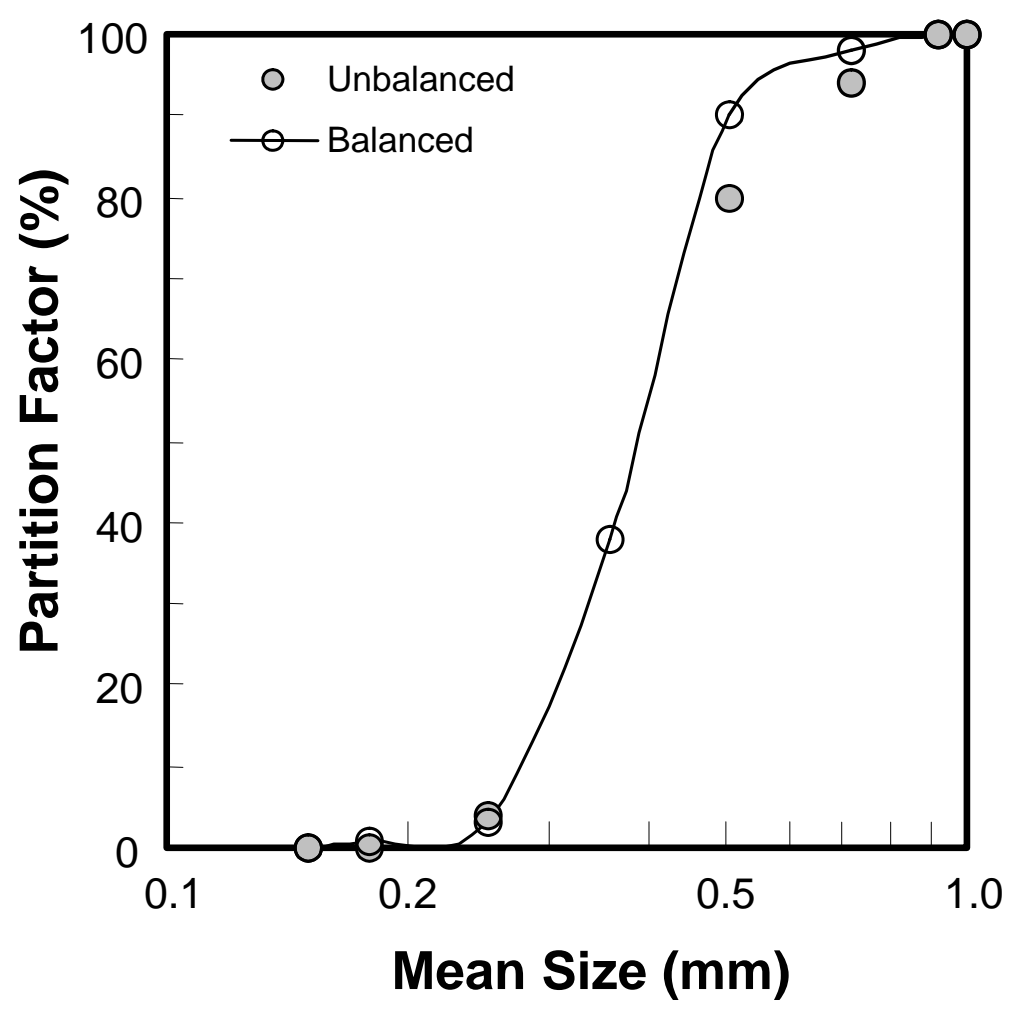

Figure 3.1. Example of a CrossFlow partition curve.

commonly used to quantify the efficiency of sizing units. A lower number represents a steeper curve and thus a better separation. A vertical line represents a perfect separation. The imperfection (I) is determined by:

$$
\mathrm{I}=\left(\mathrm{d}_{75}-\mathrm{d}_{25}\right) / 2 \mathrm{~d}_{50}
$$

Using this approach, the test results were analyzed to compare the performance of each separator. These results, which are compared in Figure 3.2, show the imperfection of each unit as a function of dry feed rate. The test results indicate the CrossFlow unit consistently performed at a higher level of efficiency (lower imperfection). Close examination of the test results indicated that the lower efficiency associated with the conventional classifier was due to misplacement of 


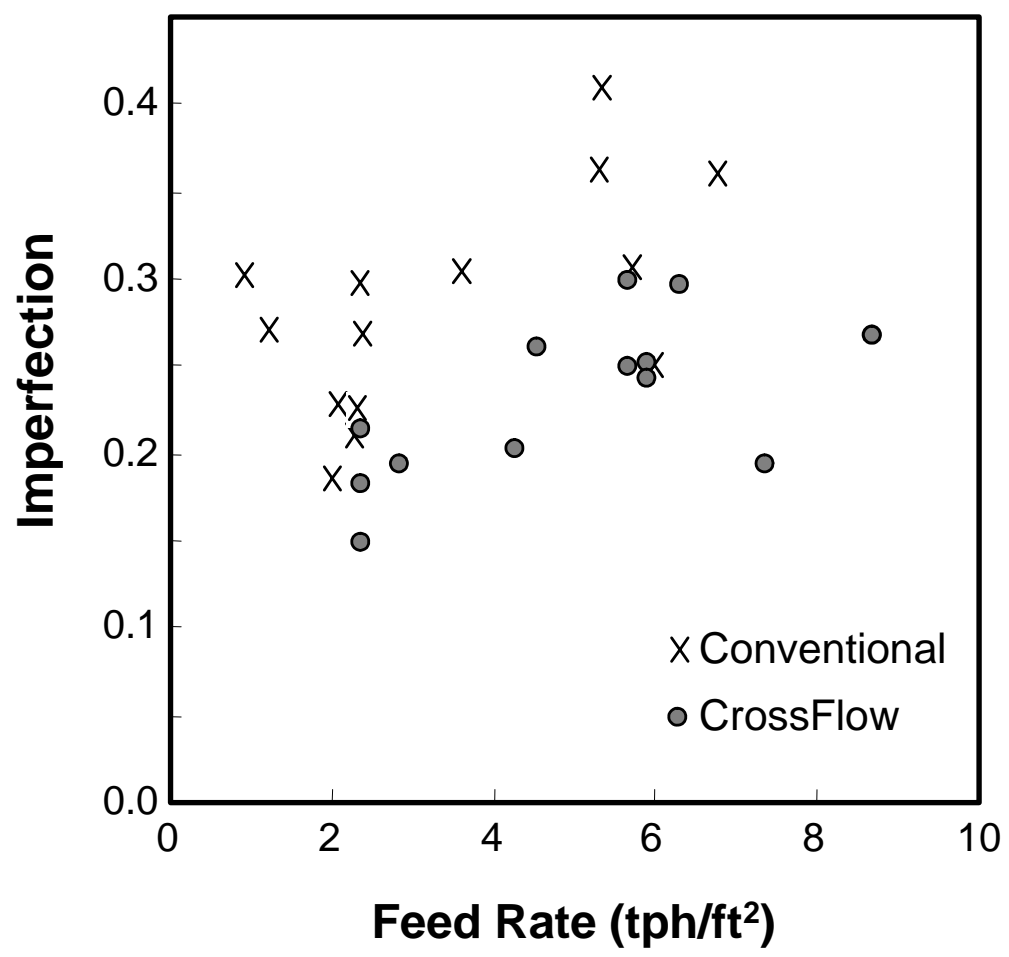

Figure 3.2. Imperfection versus superficial solids feed rate.

coarse material to the overflow product created by the higher flow rate and greater turbulence within the upper section of the conventional sizer. On the other hand, the CrossFlow hinderedbed separator maintained a uniform (laminar) flow pattern and thus the amount of misplaced material was minimized.

It is also important to note that the unique design of the CrossFlow makes it possible to accurately control the particle size cut size. (The cut size is defined as the particle size corresponding to the $50 \%$ recovery point on the partition curve, and is considered to be separation size for a given test.) As stated previously, variations in the characteristics of the feed (such as solids content) do not significantly impact the cut size since the teeter water velocity remains constant throughout the unit. As a result, the particle size cut size is controlled predominantly by the teeter water flow rate. In fact, the data in Figure 3.3 show that an 


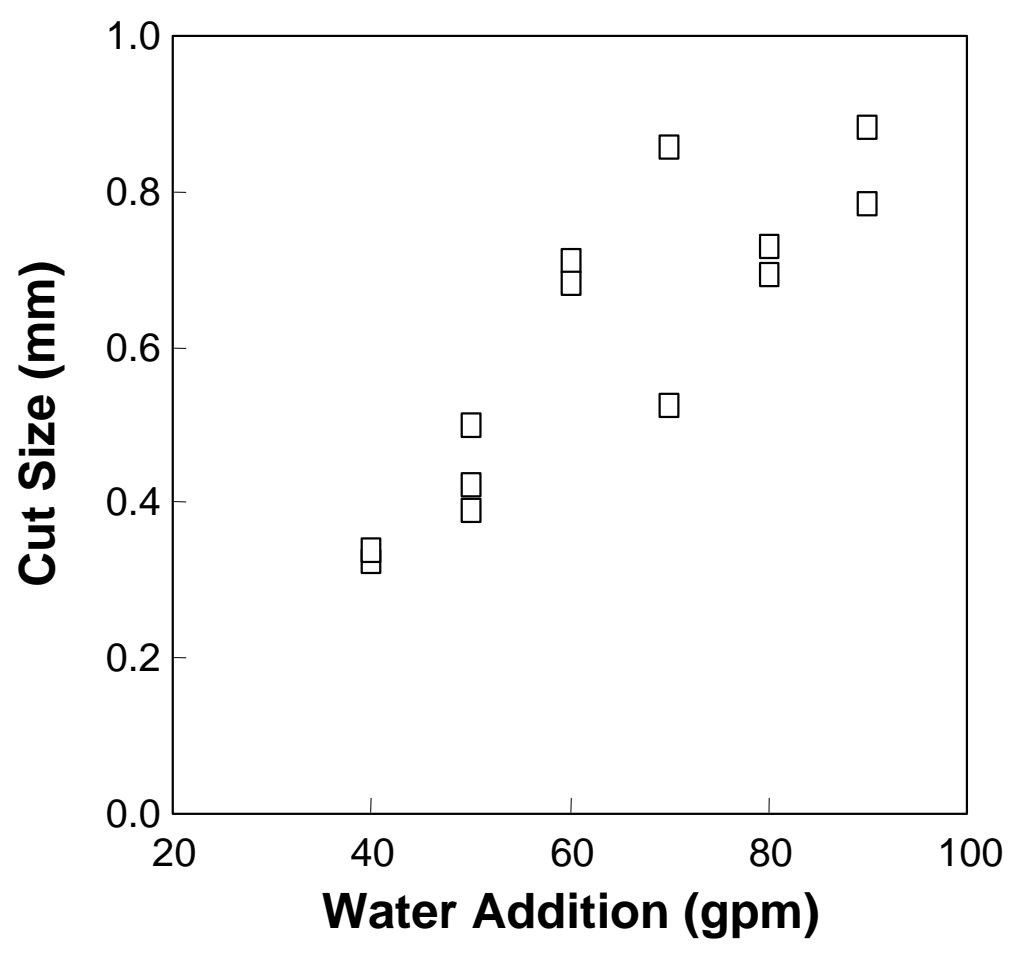

Figure 3.3. Particle cut size versus fluidization water rate.

approximately linear relationship exists between flow rate and particle cut size. As a result, online adjustment of size of the overflow and underflow products can be achieved through simple water flow control for the CrossFlow classifier.

\subsubsection{Full-Scale Prototype Test Results}

In light of the promising results obtained using the pilot-scale CrossFlow unit, a full-scale classifier at an industrial phosphate beneficiation plant was retrofit using the CrossFlow feeding system. The results obtained from this unit were then compared to those obtained from the conventional full-scale classifiers operating in parallel to the CrossFlow system at the plant. Due to fluctuations in the plant feed tonnage, the test results are reported as an average of seven sets of experiments conducted over a range of dry solids feed rates from 1270 to 1800 tph (circuit). In each test, representative samples of feed, oversize and undersize solids were collected and 
subjected to sieve analysis. The resulting size data were used to construct partition curves for both the conventional and CrossFlow units. The data points were then fit using an empirical partition function given by:

$$
P=\left(\exp \left\{\alpha\left(d / d_{50}\right)\right\}-1\right) /\left(\exp \left\{\alpha\left(d / d_{50}\right)-\exp \{\alpha\}-2\right)\right.
$$

in which $\mathrm{P}$ is the partition factor, $\mathrm{d}$ the particle size, $\mathrm{d}_{50}$ the particle size cutpoint (defined at $\mathrm{P}=50 \%$ ), and $\alpha$ is a parameter that reflects the sharpness of the size separation (defined as the slope at $\mathrm{P}=50 \%$ ). Note that a larger value of $\alpha$ indicates a sharper (more efficient) particle size separation.

The results of the side-by-side comparison of the conventional and CrossFlow classifiers are provided in Table 3.2. As expected from the laboratory and pilot-scale data, the full-scale test results show that the CrossFlow reduced the particle cut size from 729 to 362 microns while maintaining the same feed throughput. At the same time, the CrossFlow substantially improved the efficiency of sizing ( $\alpha$ increased from 3.4 to 8.1). In fact, the amount of misplaced coarse (+35 mesh) solids in the fine product overflow was reduced by more than five-fold (from 9.0\% to $1.7 \%$ ). These impressive results illustrate the superior performance of the CrossFlow separator for industrial classification applications.

Table 3.2. Comparison of full-scale conventional and CrossFlow classifiers.

\begin{tabular}{ccc}
\hline Test Variable & Conventional & CrossFlow \\
\hline Particle Cut Size & $29 \mu \mathrm{m}$ & $362 \mu \mathrm{m}$ \\
Alpha Value & 3.4 & 8.1 \\
Misplaced +35 Mesh & $9.0 \%$ & $1.7 \%$ \\
\hline
\end{tabular}




\subsection{Phosphate Upgrading Using the HydroFloat Concentrator}

\subsubsection{Pilot-Scale Test Results}

Several series of in-plant tests were conducted to assess the capabilities of the HydroFloat separator for upgrading coarse phosphate matrix. The test program was carried out using a pilotscale HydroFloat unit. Feed for the test unit was taken from an existing slurry distributor that fed an identical pair of 8-foot diameter rougher-scavenger flotation cells. Prior to flotation, the feed was reagentized with a fatty-acid/fuel oil blend and conditioned in stirred-tank conditioners at $72 \%$ solids. Soda ash was used to control pH. During testing, fluidization (teeter) water was introduced into the bottom of the separator to create a fluidized bed of phosphate particles. Air and frother were passed through a bubble generator and injected through the water distribution network. The air bubbles, which selectively attached to hydrophobic particles, created lowdensity bubble-particle aggregates that were recovered as overflow product. The hydrophilic particles (sand) were rejected as a waste stream through a discharge valve at the bottom of the unit. Twelve test runs were completed using the test conditions summarized in Table 3.3.

The results from the in-plant testing of the pilot-scale HydroFloat separator are summarized in Table 3.4. The BPL recoveries ranged from a low of $90.1 \%$ to a high of $98.2 \%$ over the range of test conditions evaluated. Under optimal conditions (i.e., highest separation efficiency), the HydroFloat provided a product grade of $11.4 \%$ insol and $64.6 \%$ BPL. These single-stage results compare very favorably to the existing two-stage rougher-scavenger flotation circuit currently in operation at the plant. The two-stage circuit historically provides a froth

product containing about $20 \%$ insol and $60 \%$ BPL. Therefore, these results indicate that the HydroFloat can achieve a comparable separation after only a single-stage of processing. 
Table 3.3. Test conditions for the pilot-scale HydroFloat concentrator.

\begin{tabular}{cccc}
\hline $\begin{array}{c}\text { Test } \\
\text { Run }\end{array}$ & $\begin{array}{c}\text { Teeter Water } \\
\text { Rate }(\mathrm{gpm})\end{array}$ & $\begin{array}{c}\text { Aeration } \\
\text { Rate }\left(\mathrm{scfm} / \mathrm{ft}^{2}\right)\end{array}$ & $\begin{array}{c}\text { Reagent } \\
(\mathrm{lb} / \mathrm{ton})\end{array}$ \\
\hline 1 & & & \\
2 & 13.4 & 1.27 & 0.80 \\
4 & 13.4 & 1.27 & 0.80 \\
5 & 10.2 & 1.27 & 0.80 \\
6 & 11.5 & 1.06 & 0.90 \\
7 & 11.5 & 1.06 & 1.00 \\
8 & 11.5 & 1.06 & 1.00 \\
9 & 11.5 & 1.06 & 1.00 \\
10 & 11.5 & 1.06 & 1.00 \\
11 & 11.5 & 0.85 & 1.00 \\
12 & 11.5 & 0.85 & \\
& 11.5 & 0.64 &
\end{tabular}

Note: Feed Rate $=1.3 \mathrm{tph} / \mathrm{ft}^{2} ;$ Feed Solids $=50 \%$

Table 3.4. Test results for the pilot-scale HydroFloat concentrator.

\begin{tabular}{|c|c|c|c|c|c|}
\hline \multirow[b]{2}{*}{ No. } & \multicolumn{2}{|c|}{ Conc. Grade (\%) } & \multicolumn{2}{|c|}{ Distribution (\%) } & \multirow{2}{*}{$\begin{array}{c}\text { Effic. } \\
(\%)\end{array}$} \\
\hline & BPL & Insol & BPL & Insol & \\
\hline 1 & 36.9 & 50.2 & 98.2 & 50.3 & 48.5 \\
\hline 2 & 46.3 & 37.6 & 98.2 & 63.3 & 61.5 \\
\hline 4 & 60.5 & 17.8 & 94.0 & 77.0 & 71.0 \\
\hline 5 & 53.0 & 26.6 & 93.0 & 84.7 & 77.7 \\
\hline 6 & 64.6 & 11.4 & 90.1 & 88.1 & 78.2 \\
\hline 7 & 59.8 & 18.7 & 96.6 & 74.9 & 71.4 \\
\hline 8 & 50.8 & 30.1 & 97.8 & 54.1 & 51.9 \\
\hline 9 & 60.4 & 17.9 & 95.8 & 77.4 & 73.1 \\
\hline 10 & 55.8 & 24.6 & 94.6 & 67.8 & 62.4 \\
\hline 11 & 56.1 & 23.3 & 97.8 & 66.5 & 64.3 \\
\hline 12 & 63.4 & 13.9 & 93.5 & 81.6 & 75.1 \\
\hline
\end{tabular}

Note: Average Feed: $\mathrm{BPL}=35.8 \%$, Insols $=51.8 \%$ 


\subsubsection{Full-Scale Prototype Test Results}

Based on these very promising results of the pilot-scale tests, several sets of follow-up tests were undertaken at the industrial plant site using a full-scale ( $8 \mathrm{ft}$ diameter) column cell that had been retrofit with the HydroFloat technology. For comparison, samples were collected from the plant conventional rougher flotation cell so that a fair performance comparison could be made.

Figures 3.4 and 3.5 show the recovery-grade curves obtained from the pilot- and fullscale HydroFloat test programs, as well as data from the conventional rougher flotation bank at the plant site. Several important observations can be made. First, the data points appear to fall along essentially the same recovery-grade curves, suggesting that the selectivity of the separation is largely dominated by the surface properties (wettability) of the particles. Second, the results suggest that the performance of the full-scale HydroFloat unit can be projected based on test data obtained from the pilot-scale test unit. This finding is particularly important for scale-up reasons. Finally, the side-by-side comparison clearly demonstrates that the HydroFloat technology is capable of providing a significantly higher recovery of valuable product than can be obtained using a comparable volume of single-stage conventional flotation cells. For the current test program, the best full-scale HydroFloat test run provided a BPL recovery of $95.9 \%$ with a product having BPL and insol contents of $68 \%$ and $7.7 \%$, respectively. In comparison, the conventional froth flotation column was able to achieve a BPL recovery of just $82.8 \%$. Thus, additional stages of conventional scavenger flotation are required at the plant in order to improve the recovery to an acceptable level. 


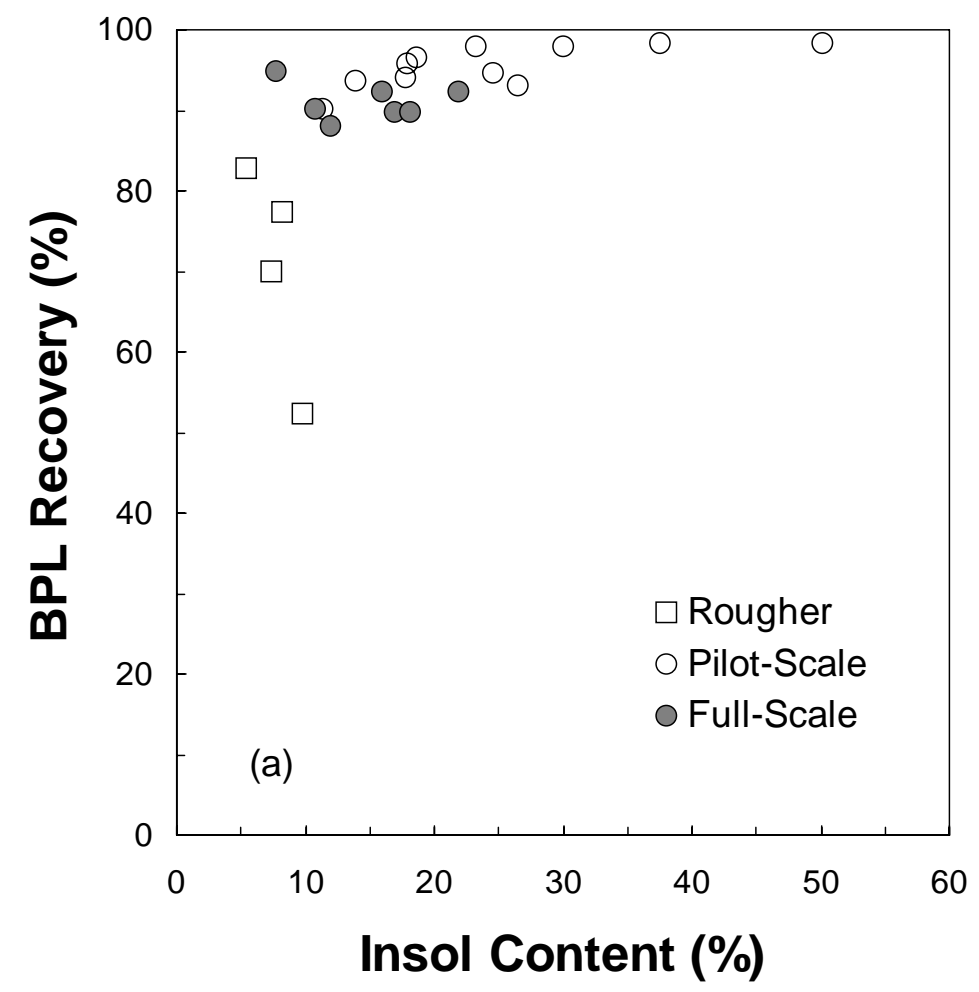

Figure 3.4. Recovery versus insol content for different test runs.

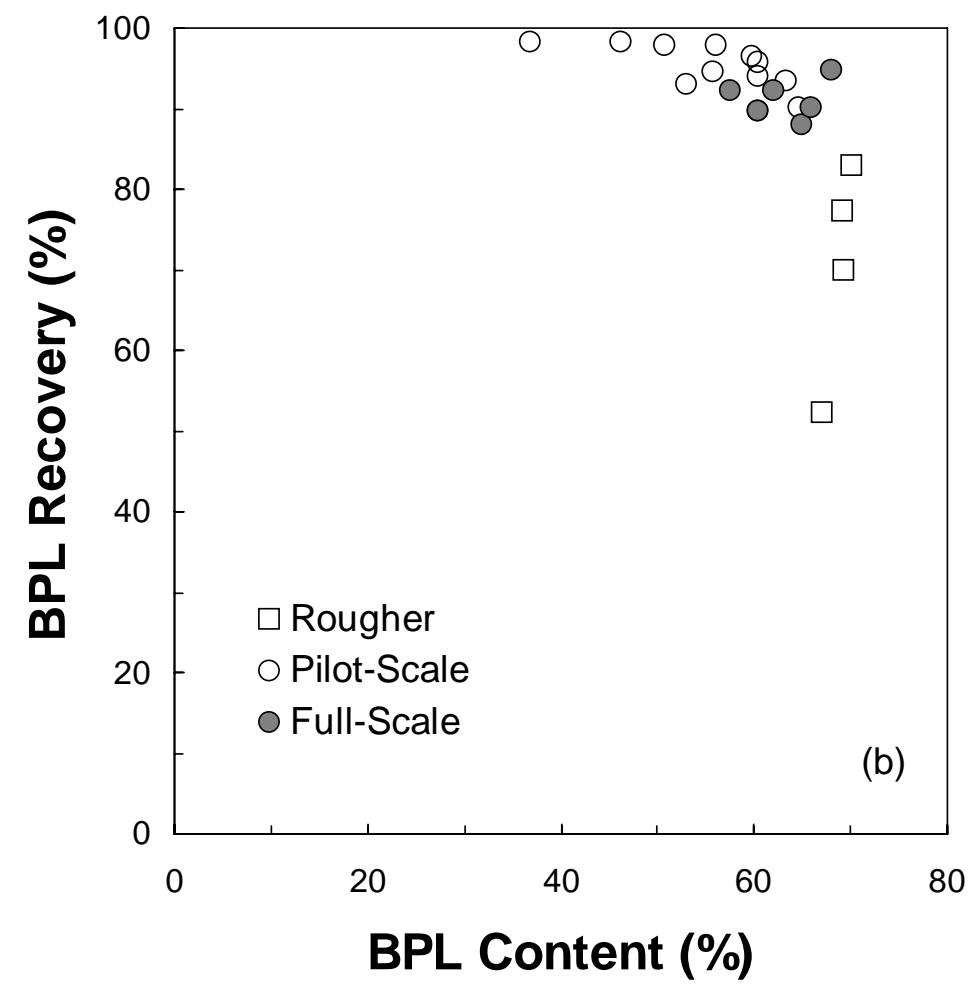

Figure 3.5. Recovery versus BPL content for different test runs. 
The results obtained from the industrial site indicate that the HydroFloat also offers significant cost advantages by consuming less electrical power, process water, and chemical reagents than conventional processes. For example, Table 3.5 compares the expected power and reagent usage for the HydroFloat and conventional circuits for the test site described above. In this case, the installation of the HydroFloat technology would be expected to reduce the net horsepower requirement by $8.4 \%$. In addition, the HydroFloat would require $40 \%$ less frother, $20 \%$ less fatty acid/fuel oil mixture (rougher), and 100\% less fuel oil (scavenger).

Table 3.5. Comparison of power and reagent demand.

\begin{tabular}{cccc}
\hline & $\begin{array}{c}\text { HydroFloat } \\
\text { Circuit }\end{array}$ & $\begin{array}{c}\text { Existing } \\
\text { Circuit }\end{array}$ & $\begin{array}{c}\text { Net } \\
\text { Change }\end{array}$ \\
\hline Power Usage: & & & --- \\
\hline Water (HP) & 46.6 & 92.4 & --- \\
Air (HP) & 38.0 & 0.0 & $-8.4 \%$ \\
Net Total (HP) & 84.6 & 92.0 & \\
\hline Reagents: & & & $-40.0 \%$ \\
\hline Frother (lb/t) & 0.05 & 0.08 & $-20.0 \%$ \\
FA/FO (lb/t) & 0.80 & 1.00 & $-100 \%$ \\
FO (lb/t) & 0.00 & 0.60 &
\end{tabular}




\subsection{Fine Coal Cleaning Using the CrossFlow Concentrator}

\subsubsection{Pilot-Scale Test Results}

This task involved the testing of a pilot-scale CrossFlow separator to determine whether the installation of one or more full-scale units could be justified at a new plant in Kentucky. Since the plant did not yet exist, the pilot-scale testing was performed at a nearby facility treating a similar coal feed. The goal of this effort was to determine the anticipated product yield and grade, combustible recovery, and feed capacity of the test unit in order to predict the expected performance of a full-scale prototype.

The 9 x 16 inch CrossFlow separator was transported from the manufacturer's site to the coal preparation plant and was installed with assistance provided by the plant operators and mechanics. Feed was supplied to the unit through a 2-inch feed line connected to the existing coal spiral slurry feed distributor. A slurry splitter fabricated from PVC pipe with a tee and valves was used to regulate the feed to the unit, with the remaining slurry reporting to the spiral circuit. Underflow and overflow material was discharged to sizing screens in the plant, located on a level below the unit. Plant compressed air and electrical power were connected to the separator for the automated control system. The separator was automatically controlled through the use of a simple PID control loop, which includes a pressure sensor mounted on the side of the separator to measure the relative pressure (level), a single-loop PID controller, and a pneumatic pinch valve to control the underflow discharge to maintain a constant bed pressure (level). Clarified water was connected to the separator to create the fluidized teeter bed of solids.

Preliminary shakedown testing of the pilot-scale unit was conducted after completing the installation to resolve any unexpected operational problems that could arise. Once the circuit was operational, two series of detailed tests were then conducted. The first series of tests were 
performed to investigate the effects of the key design variables on separator performance and to simultaneously define the overall grade and recovery curve, while the second series of tests were conducted to investigate the effects of key operating parameters. The most important operating variables were found to be teeter bed pressure and fluidization water rate. The coal/rock interface, or teeter bed surface, was adjusted to different levels (i.e. different bed pressure) for each steady-state test. Fluidization water was adjusted to fine tune the separation. Other variables examined included solids mass feed rate and volumetric slurry feed rate. For each test, samples were taken from the feed, overflow, and underflow streams after conditions were stabilized. The samples were analyzed for ash and sulfur contents on a size-by-size basis.

As shown in Table 3.6, nine test runs were completed during the on-site test work. The experimental results are shown graphically in Figures 3.7 and 3.8. The results are plotted as with the passing 100 mesh material mathematically removed from the data. This approach is acceptable as it is expected that the clean coal product will be deslimed in the plant at 100 mesh $(0.150 \mathrm{~mm})$ using sieves and the fine material upgraded by flotation.

Table 3.6. Test conditions used for the on-site pilot-scale testing of the CrossFlow unit.

\begin{tabular}{|c|c|c|c|c|c|}
\hline \multirow{2}{*}{$\begin{array}{c}\text { Test } \\
\text { Number }\end{array}$} & \multicolumn{3}{|c|}{ Feed } & \multirow{2}{*}{$\begin{array}{l}\text { Level } \\
\text { inches }\end{array}$} & \multirow{2}{*}{$\begin{array}{c}\text { Water } \\
\text { gpm }\end{array}$} \\
\hline & \% Solids & tph & gpm & & \\
\hline 1 & 32.55 & 1.83 & 20 & 14.5 & 8 \\
\hline 2 & 34.44 & 1.95 & 20 & 20.0 & 8 \\
\hline 3 & 35.24 & 2.00 & 20 & 10.0 & 8 \\
\hline 4 & 35.71 & 1.73 & 17 & 10.0 & 9.5 \\
\hline 5 & 32.90 & 2.22 & 24 & 14.5 & 9.5 \\
\hline 6 & 32.71 & 1.84 & 20 & 20.0 & 9.5 \\
\hline 7 & 35.21 & 2.00 & 20 & 20.0 & 6.5 \\
\hline 8 & 34.10 & 1.93 & 20 & 14.5 & 6.5 \\
\hline 9 & 33.55 & 1.89 & 20 & 10.0 & 6.5 \\
\hline
\end{tabular}




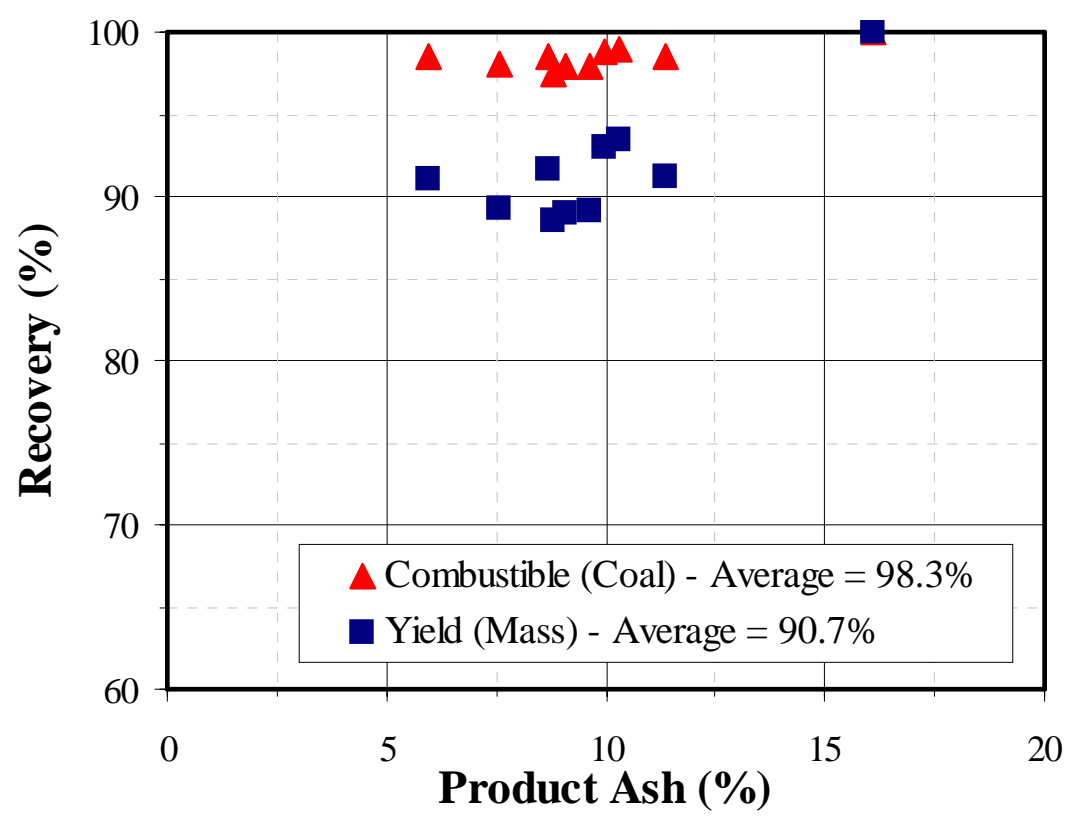

Figure 3.7. Recovery versus product ash for the plus 100 mesh coal.

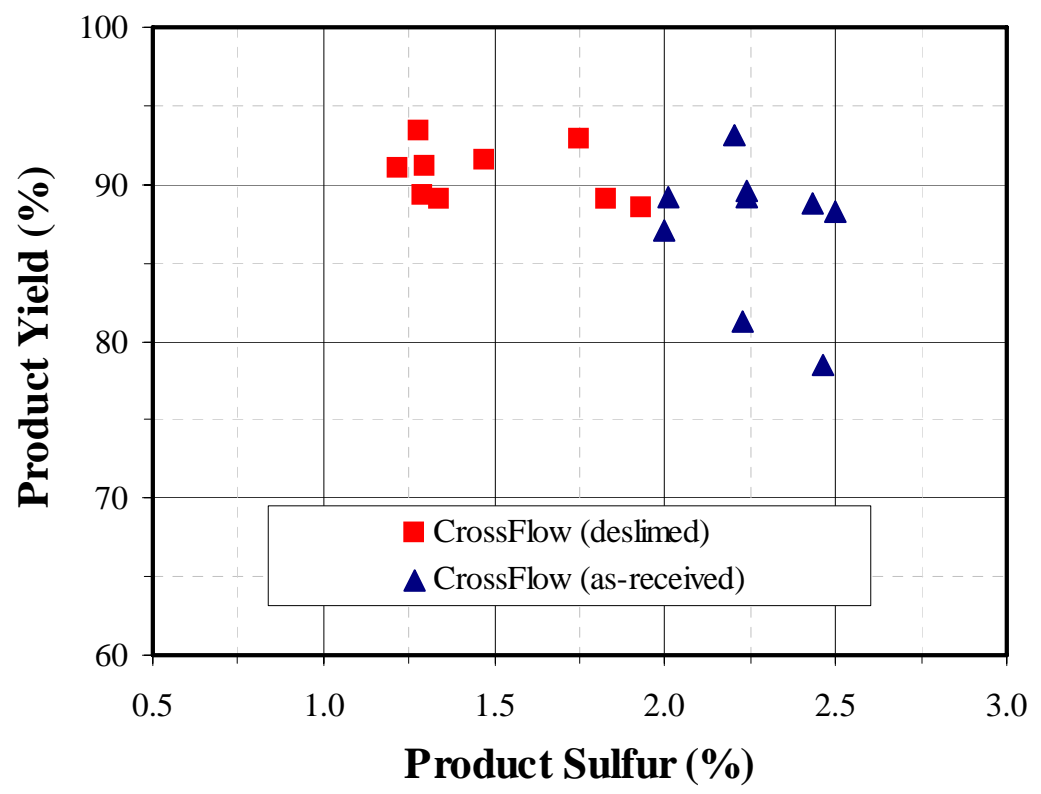

Figure 3.8. Mass yield versus product sulfur for the plus 100 mesh coal. 
As shown in Figure 3.7, the pilot-scale test work was clearly able to define the expected grade and recovery curve for this particular coal. Specifically, the CrossFlow separator was capable of producing a clean coal product having $6-11 \%$ ash at a combustible recovery of greater than $97 \%$ (when deslimed at 100 mesh). At the maximum separation efficiency, the combustible recovery for this application approached 98\%. The data presented in Figure 3.8 indicates that the sulfur content of the corresponding product was $1.50 \%$.

\subsubsection{Full-Scale Prototype Test Results}

Following the successful completion of the pilot-scale testing, the participating coal company elected to install a full-scale prototype CrossFlow separator for cleaning the intermediate size fraction $(2.0 \times 0.25 \mathrm{~mm})$ of raw coal for a new 650 tph green-field preparation plant in Kentucky. The expected material balance for the prototype circuit is shown in Figure 3.9. The feed to the prototype unit was expected to contain approximately 175 tph of feed coal at about 50\% solids. The pilot-scale test work demonstrated the ability of the CrossFlow separator to handle this entire flow using a single-stage $9 \times 9 \mathrm{ft}$ separator (offering $81 \mathrm{ft}^{2}$ of cross-sectional area at a normalized feed rate of $2.1 \mathrm{tph} / \mathrm{ft}^{2}$ ). The remaining tonnage in other size fractions fed to the plant were treated with heavy medium cyclones (2 inch $x 2 \mathrm{~mm}$ ) and conventional froth flotation cells $(0.25 \mathrm{~mm} \times 0)$.

The CrossFlow separator was manufactured by Eriez Manufacturing and installed in the new preparation plant by the participating coal company. A photograph of the installed prototype separator is shown in Figure 3.10. The clean coal product (overflow) from the unit is deslimed at 65 mesh $(0.25 \mathrm{~mm})$ using a sieve screen and horizontal vibrating screen, combined with the flotation product, and dewatered in a screen-bowl centrifuge circuit. The reject (underflow) is dewatered on horizontal vibrating dewatering screens and directed to the plant rejects conveyor. 
CROSSFLOW CIRCUIT - MATERIAL BALANCE

175.0 stph Option

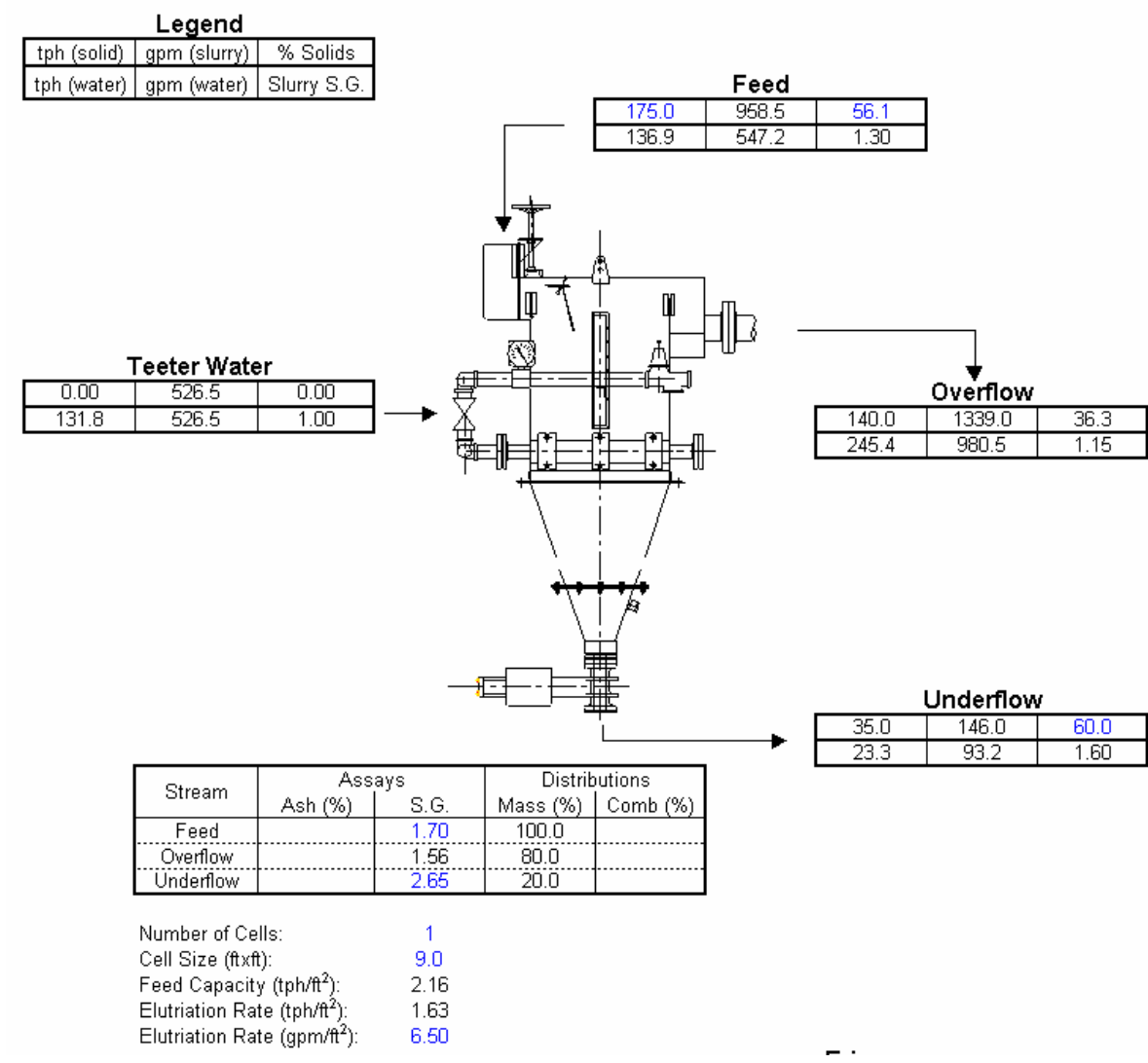

Figure 3.9. Mass balance sheet for the full-scale prototype CrossFlow.

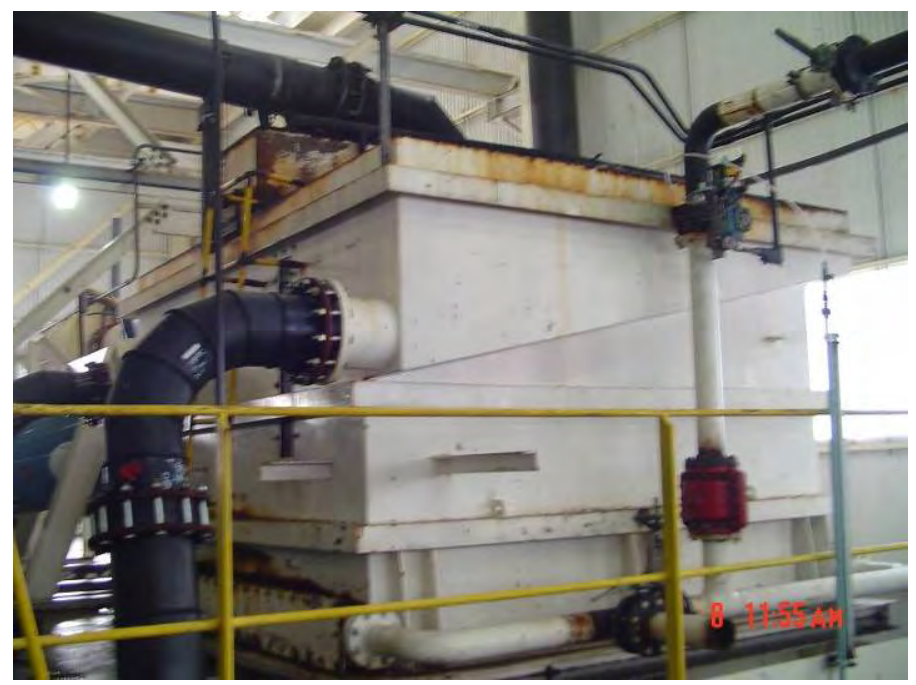

Figure 3.10. Photograph of the installed full-scale CrossFlow separator. 
Shakedown testing for the prototype unit included a visual inspection of all the components after the installation, operating the unit on water to check the control devices, and tuning the control system after adding raw coal feed. The teeter-bed density, which controls the separating density, is automatically maintained by a PID controller with an input from a differential pressure (DP) cell transmitter located in the lower section of the separating zone. The output from the controller manipulates a proportional valve on the underflow discharge pipe. The elutriation water is controlled manually using a simple valve arrangement. During start-up and commissioning, the unit produced a clean coal product with an ash content of approximately $10 \%$ at a combustible recovery of better than $90 \%$.

After shakedown testing, three sequential series of evaluations were conducted during the 11 month period after start-up. In each series of tests, the feed, product, and reject streams were sampled during a normal operating shift. A sample of the feed was also taken and subjected to float-sink analysis so that the theoretical best level of performance could also be established for this particular feed coal. The results from the first series of "preliminary tests" are presented in Figure 3.11. The performance data show that the combustible recovery regularly exceeded $90 \%$ with product ash values ranging between $10 \%$ and $12 \%$. While these results were very good, the second series of “detailed tests” were conducted with the objective of further improving recovery while maintaining product grade. The evaluations were conducted while running the unit at the highest available teeter-bed pressure (bed level) while varying the elutriation water rate. The maximum level was limited by the calibration of the existing DP cell transmitter. As shown in Figure 3.11, the detailed tests resulted in an incremental improvement in separation performance. By operating with the teeter-bed at the highest level, the average combustible recovery and yield improved by nearly $2 \%$, while the product ash remained in the $10 \%$ to $12 \%$ range. This series of 


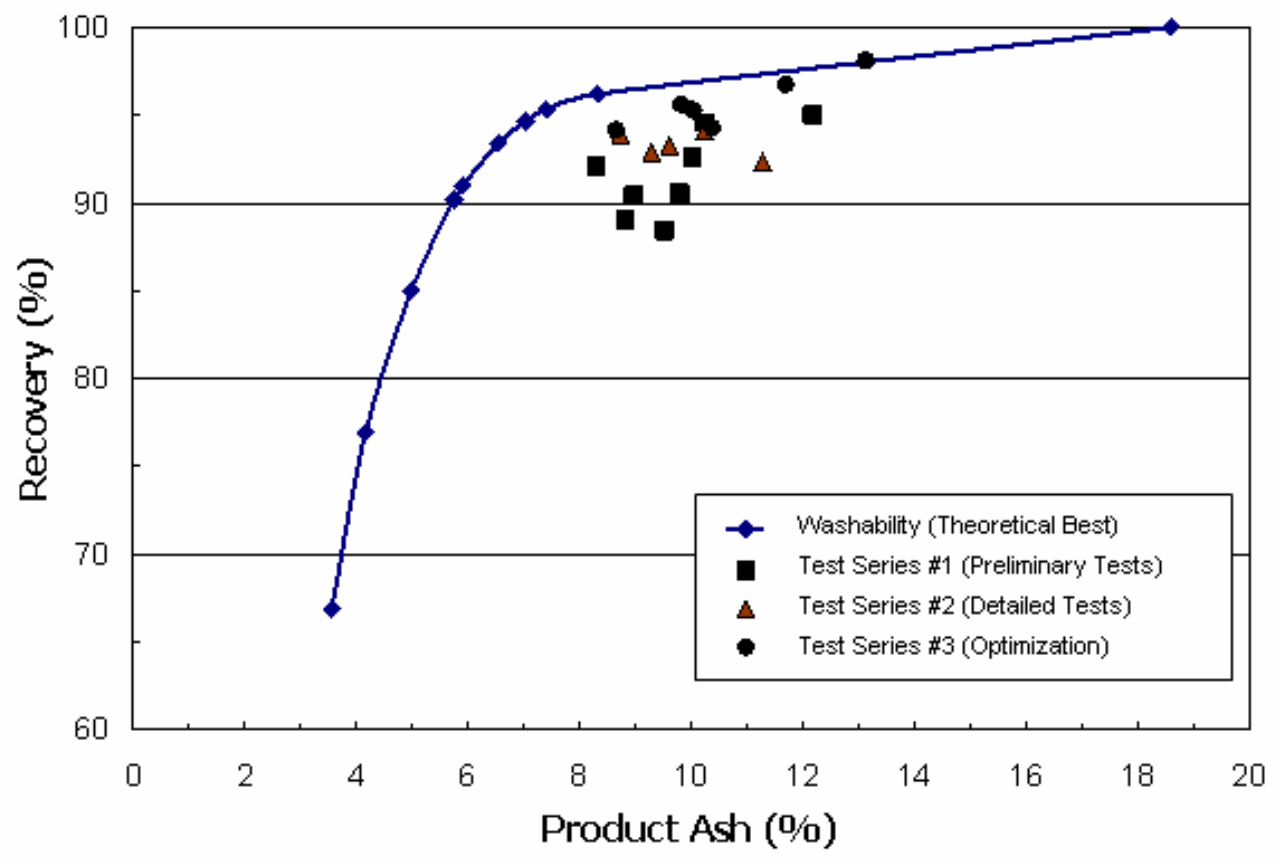

Figure 3.11. Experimental results from three series of full-scale CrossFlow tests.

testing suggested that further performance improvements could be realized by increasing the teeter-bed level.

The third series of testing was performed after recalibration of the DP cell transmitter so that the unit could be operated at higher teeter-bed levels than those that were used during the first two series of tests. The results of these "optimization tests" are also presented in Figure 3.11. By operating the unit at a higher teeter-bed level (higher densities), the recovery was improved by an additional 2 percentage points. In fact, this mode of operation provided a separation performance that was in very good agreement with that projected based on the pilotscale experiments. The systematic approach of optimizing the CrossFlow separator resulted in an average increase in product mass yield of over 4 percentage points, which equates to about 5.9 tph of additional clean coal. Using the current typical market price for thermal coal of $\$ 50.00$ per 
ton and scheduled production of 4,000 hours per year, this improvement increased the annual revenue from this circuit by about $\$ 1.2$ million.

After optimizing the performance of the unit, a long-duration test run was performed under the optimum conditions identified from the earlier test runs. In this case, sample increments were collected at regular intervals during an 8-hour shift for the feed, product, and reject streams. The resultant samples were combined and subjected to laboratory analyses. The results obtained from this test run are shown in Table 3.7. The separator produced a clean coal ash of about $9.5 \%$ at a mass yield of $84.7 \%$ and combustible recovery of $93.5 \%$. At the same ash content, the float-sink data for this particular sample was found to produce a theoretical clean coal yield of $87.1 \%$. As such, the CrossFlow separator provided an exceptionally good organic efficiency of $97.3 \%$ for this particular application.

Table 3.7. Results of a long duration ( $8 \mathrm{hr}$ ) CrossFlow test under optimum conditions.

\begin{tabular}{ccccc}
\hline $\begin{array}{c}\text { Feed Ash } \\
(\%)\end{array}$ & $\begin{array}{c}\text { Product Ash } \\
(\%)\end{array}$ & $\begin{array}{c}\text { Reject Ash } \\
(\%)\end{array}$ & $\begin{array}{c}\text { Mass Yield } \\
(\%)\end{array}$ & $\begin{array}{c}\text { Combustible } \\
\text { Recovery (\%) }\end{array}$ \\
\hline 17.95 & 9.51 & 64.80 & 84.74 & 93.46 \\
\hline
\end{tabular}




\subsection{CONCLUSIONS}

Hydraulic separators are used in the mineral and coal processing industries to classify and/or upgrade particles according to size, shape or density. Unfortunately, current designs are typically inefficient, resulting in substantial losses of valuable resources. In response to this problem, a new generation of hydraulic separators, known as the CrossFlow Classifier and HydroFloat Separator, has been developed based on fundamental processing engineering knowledge. In order to promote industry implementation, a field study was undertaken (i) to further develop these new technologies through systematic pilot-scale testing of key design and operating variables and (ii) to demonstrate the improved performance at industrial sites using full-scale prototypes.

The pilot-scale data collected to date indicate that these high-efficiency separators can substantially improve the performance of classification and concentration circuits. In light of these promising results, full-scale prototypes of the CrossFlow and HydroFloat technologies have been purchased by mining companies for further testing and evaluation. Two of the prototype units have been installed by a major U.S. phosphate producer and one by a major coal producer. The preliminary data obtained from the full-scale evaluations also demonstrate that these technologies offer significant improvements in terms of metallurgical performance (e.g., higher recovery and throughput capacity) and lower operating cost (e.g., lower consumption of electrical power, process water, and chemical reagents) than conventional processes. A complete engineering assessment of the field testing data is currently underway to fully evaluate the process capacities and cost-benefit of these high-efficiency technologies. 


\subsection{REFERENCES \& BIBILOGRAPHY}

Denin, W.L., and Wilson, V.H., 1948, "Cleaning Anthracite Silt For Boiler Fuel With Humphreys Spiral Concentrator,” Transactions, AIME/SME, Vol. 175 p. 328.

Heiskanen, K., 1993, Particle Classification, Powder Technology Series, Chapman and Hall, London, England.

Kapur P.C. and Meloy, P.T., 1998, "Spirals Observed", International Journal of Mineral Processing, Vol. 53, pp. 15-28.

Leonard III, J.W., 1991, Coal Preparation, Fifth Edition, SME, Littleton, Colorado.

Littler, A., 1986, "Automatic Hindered-Settling Classifier for Hydraulic Sizing and Mineral Beneficiation,” Transactions, Institute of Mining and Metallurgy, Vol. 95, pp. 133-138.

Luttrell, G.L., 1998, “Coal Preparation,” Class Notes from Virginia Polytechnic Institute \& State University.

Mackie RI, Tucker P and Wells A, 1987, "Mathematical model of the Stokes Hydrosizer", Transactions of the Institute of Mining and Metallurgy Sect C, Vol. 96, pp. 130-136.

North Carolina State Minerals Research Laboratory, Publication No. 92-24-P, 1992, "Preliminary Desliming Tests w/ NC Phosphate Using a Pilot-Scale Linatex Hydrosizer," Prepared By: Schlesinger, L. and Hutwelker, J.

Phoenix Process Equipment Company, 2003. Process Equipment, Systems and Solutions for Industry. Available at: www.dewater.com/en/equip/class.htm. Accessed August 9, 2004.

Weiss, N.L., 1985, SME Mineral Processing Handbook. American Institute of Mining, Metallurgical and Petroleum Engineers, Inc., Chapter 3, Vol. 1.

Wills, Barry A., 1992. Mineral Processing Technology $5^{\text {th }}$ Edition. Pergamon Press. Tarrytown, New York.

Florida Institute of Phosphate Research, Publication No. 02-070-098, "Development of Novel Flotation-Elutriation Method for Coarse Phosphate Beneficiation”, Prepared by Soto, H. of Laval University, June 1992.

Florida Institute of Phosphate Research, Publication No. 02-137-188, "In-Plant Testing of the HydroFloat Separator For Coarse Phosphate Recovery”, Prepared by Eriez Magnetics, July 2002.

Gaudin, A., Grob, J. and Henderson, H., 1931, “Effect of Particle Size in Flotation,” Technical Publication No. 414, AIME. 
Heiskanen, K., 1993, Particle Classification, Powder Technology Series, Chapman and Hall, London, England.

Jameson, G.J., Nam, S. and Young, M.M., 1977, "Physical Factors Affecting Recovery Rates in Flotation,” Minerals Science and Engineering, Vol. 9, No. 3, pp. 103-118.

Lewis, R.M., 1990, "The Lewis Hydrosizer," NC State Minerals Research Laboratory Publication No. 81-12-P.

Littler, A., 1986, "Automatic Hindered-Settling Classifier for Hydraulic Sizing and Mineral Beneficiation,” Transactions, Institute of Mining and Metallurgy, Vol. 95, pp. 133-138.

Morris, T.M., 1952, "Measurement and Evaluation of the Rate of Flotation as a Function of Particle Size,” Mining Engineering, Vol. 4, No. 8, pp. 794-798.

North Carolina State Minerals Research Laboratory, Publication No. 92-24-P, 1992, "Preliminary Desliming Tests w/ NC Phosphate Using a Pilot-Scale Linatex Hydrosizer," Prepared By: Schlesinger, L. and Hutwelker, J.

Rubinstein, J.B., 1995. Column Flotation: Processes, Designs and Practices. Gordon and Breach Science Publishers, United States.

Soto, H. and Barbery, G., 1991, "Flotation of Coarse Particles in a Counter-Current Column Cell,” Minerals and Metallurgical Processing, Vol. 8, No. 1, pp. 16-21.

Wills, Barry A., 1992. Mineral Processing Technology $5^{\text {th }}$ Edition. Pergamon Press. Tarrytown, New York.

Young, P., 1982, “Flotation Machines,” Minerals Magazine, Vol. 146, No. 1, pp. 35. 